R. Hlstórla, Såo Paulo, n. 127-128, p. 141-162, ago-dez/92 a jan-jul/93.

\title{
SINKINGS, SAILORS, SOLDIERS, SPICE: O CORPO ENCOBERTO DO PORTUGUÊS NA INDIA
}

\author{
K. David Jackson *
}

RESUMO: Neste ensajo de interpretaçăo do simbolismo de viagens e de contatos culturais e linguisticos durante o perfodo dos descobrimentos, o autor dá relevo ao tema da identidade, examinamdo atraves da significaçåo do corpo. Apresenta exemplos folclóricos de culturas mistas, ou miscigenadas, na Ásia, como a indo-portuguesa, que resultaram dos contatos entre ocidente e oriente. Aproveitando-se de uma teorizaçăo do barroco, o autor estuda no exemplo de vidas de santos o conceito do corpo dividido entre a unidade/perfeiçato e a perda ou desmembramento. A recuperaçato da identidade ocidental perdida dificulta a valorização da cultura crioula, herança das viagens.

PALAVRAS-CHAVE: crioulo, indo-português, corpo, identidade, viagens.

Quem aceitasse o mistério do amor, aceitava o da morte; quem aceitasse que um corpo que se ignora cumpre no entanto o seu destino, entāo aceitava que o nosso destino nos ultrapassa... e com isso ultrapassamos o que sabemos de nós. Clarice Lispector, Uma Maçã no Escuro (1947: 189).

Se kera pervos, Au lo lava mea tera, Mea korpo fia barko, Brasso fia vala.

Nevill Manuscript 50/18.

Do início do século XVI até meados do século XVII, todos os anos uma esquadra portuguesa safa de Lisboa com destino à Ásia, chegando a Goa, na Índia, em setembro. No seu apogeu, no final do século XVI, o império maritimo portuguess estendia suas rotas através do Cabo da Boa Esperança, indo até Goa, e, mais além, até Malaca, Macau e Japão. Essas rotas expandi-

- Professor do Department of Spanish and Portuguese - Yale University 
JACKSON, K Daviđ. Sinkings, sailors, soldiers, spice: o corpo encoberto do portuguess na India.

ram não somente as fronteiras da Europa renascentista, mas também alteraram as identidades dos viajantes. As narrativas de encontros culturais que produziram podem ser lidas mais pelo que revelam da identidade portuguesa do que como documentos do modo como o ocidente via a Ásia. Com o tempo, os portugueses na índia criaram uma instável identidade eurasiática e mestiça que foi reivindicada por grupos, por exemplo, formados por indianos, portoindianos e goanos, sem nunca terem obtido reconhecimento oficial. Língua crioula e manifestaçōes folclóricas são đuas áreas na qual a cultura indo-portuguesa ainda é praticada; e em Goa, o estilo indo-portugues está sendo promovido através da arquitetura, culinária e costumes locais. Atualmente, entretanto, a presença portuguesa na Ásia só pode ser percebida através de sua auséncia: as relíquias e os vestígios que transformam a história em arqueologia e a cultura em semiótica. As diferenças culturais entre os diversos povos na Ásia que se consideram portugueses são marcantes e sobrevivem principalmente no ámbito da memória, do ritual e até da patologia. $O$ tema do corpo e seus códigos fornece um ponto de vista excepcional para interpretações sugestivas de algumas forças marcantes das transformaçōes culturais perpetradas pelas viagens, além de ser uma abordagem alternativa para a mudança de uma identidade portuguesa para uma nova identidade eurasiática ou indo-portuguesa ${ }^{1}$.

A minha pesquisa sobre trađiçōes folclóricas e literárias na Ásia, iniciada em Sri Lanka em 1973, mostra que as narrativas orais e as músicas levadas pelos navios portugueses tiveram um papel central na criaçăo e preservação de uma expressão cultural indo-portuguesa distinta, desenvolvida através dos anos de contato ${ }^{2}$. O texto folclórico surgido deste contato espalhou-se pela sociedade indo-portuguesa, criando novas formas de identidade cultural e coesão social. Os versos, estórias, provérbios, charadas e músicas que caracterizam a cultura indo-portuguesa são a expressão de um sincretismo cujo material provém de fontes portuguesas, africanas e asiáticas $^{3}$. A nível local, esse folclore mantinha-se em comunidades costeiras mistas habitadas por pessoas que chamavam a si mesmas de portugueses, e

1 Esse ensaio sobre os portugueses na Indin foi preparado como contribuiçáo ao Seminário Sul Asiático sobre o tema "Corpos e Fronteiras", dirigido pelo Dr. Patrick Otivelle (Centro de Estudos Asiáticos, Universidade do Texas em Austin).

2 JACKSON, Kenneth David. Sing Without Shame: Oral Tradition in Indo-Portuguese Creole Verse. Amsterdam and Macau: John Benjamins and Cultural Institute of Macau, 1990.

3 Para uma leitura lingüistica desse sincretismo, ver Hancock, lan F. "Mallacean Creole Portuguese: African, Asian or European?" Anthropological Linguistics 17 (1975): 211-36. 
R. IILsória, São Paulo, n. 127-128, p. 141-162, agu-dez/92 a jan-jul/93.

falavam uma língua portuguesa pidgin ou crioula. Tendo em vista essa mistura racial, religiosa e cultural, a identificaçāo que faziam de si como portugueses representava não só uma deformação do sentido da nacionalidade do descobrimento, mas também indicava uma viagem ou migração de suas identidades para uma realidade eurasiática ou mestiça diversa. Não é estranho que esses grupos se identificassem com os portugueses, como nota Ian R. Smith, já que estes ocupavam o topo da pirâmide social ${ }^{4}$. O que não esatva claro, no desembarque permitido da civilização portuguesa, era o enigma de um novo paradigma afro-asiático. As categorias de identidade indo-portuguesa ou eurasiática, que se interpenetram, nāo pertencem nem a um nem ao outro. O sociólogo Michael Roberts, natural de Sri Lanka, estudou a população crioula de seu país e concluiu que se tratava de pessoas que não se encaixavam em nenhuma categoria ou contexto nacionais, a não ser o delas mesmas 5 .

Cançōes comunitárias e poesia popular ainda sobrevivem como o núcleo vivo de uma síntese cultural que fala através de metáforas, símbolos, sonhos e desejos retirados de 500 anos de interação portuguesa com a Ásia ${ }^{6}$. Surpreendentemente, povos, costumes e línguas ainda sobrevivem espalhados pelos pequenos territórios, fortes, igrejas e comunidades ao longo da costa da Índia e de Sri Lanka, de Diu a Batticaloa ${ }^{7}$. A expansão marítima difundiu as tradiçōes portuguesas nessas regióes que se tornaram o solo onde ocorreu a fusāo espacial e cultural dos povos portugueses, africanos e asiáticos. Tal fusão aparece em um verso crioulo:

4 SMITH, lan Russel. "Sri Lankı Creole Portuguese phonology". Dissertaçăo, Comell University, 1977: 13.

5 O cidadh̆o holandès e portıguês sño definidos e comparndos em Tissa Fernando, "The Burghers us Ceylon", The blending of races: Marginality and identity in world perspective. Noel P. Gist e Anthony D. Dworkind, ed. Nova York: John Wiley \& Sons, 1972: 61-78. Para uma definiçåo sociologica atual da identidade inco-purtuguesa, ver ROBERTS, Michael, RAHEEM, Ismeth e COLIN.THOME, Percy. People Inbetween: The Burghers and the Middle Class in the Transformation within Sri-Lanka 1790s-1960s. vol. 1. Ratmalana: Sinvadaya, 1989.

6 As citaçoes da poesia crioula fornm retiradas do manuscrito Nevill da poesia crioula de Sri Lanka, transcritas e traduzidas em Sing Without Shame; de MONIZ, António F., "The Negroes and St. Benedict's Feast", In the Mission Field. Bumbny: Time Press, 1925: 570-72; e de Cartigas ne o Lingua de Portuguez (Impressu ne Matre, Sridhnra Press, 23 de Juni, 1914), transcritas e traduzidas em JACKSON, K. David, "Indo-Portuguese Cantigas: Oral traditions in Ceylon Portuguese Verse", Hispania 74.3: 618-526.

7 Fazem parte do grupo de pesquisadores de campo das comunidades indo-portuguesas e da língua crioula, desde 1970, Alan Baxter, J. C.tancy Clements, M. H. Goonatilleka, D.E. Hettiaratchi, Dennis McGilvmy, lan R. Smith, Laurentiu Theban, Isabel Tomás e o autor. 
JACKSON, K. David. Sinkings, sailors, soldiers, spice: o corpo encoberto do português ns Indis.

Seus beiços cumprido, Seus olhos torcido, Rosto de rabana, Tem cafre de Inhabano.

Moniz 1925: 572

Em Cantiga de Ceilão, o poeta portugues Jorge de Sena considerou os significados possiveis atuais de textos folclóricos recuperados em Sri Lanka. Ele percebeu as diferenças entre a identidade indo-portuguesa que aparece no texto popular e aquela da memória cultural de um povo esquecido e isolado, abandonado por um país que eles nunca conheceram:

Escritos em caracteres tamis, e transcritos com fonética inglesal por quem mal sabe a língua em que soavam.../ estes versos emergem com uma tranqüilidade/ terrivel de língua morta a desfazer-se/ e cujos ossos restam dispersos num e de um rimance/ cantado há quatro séculos numa terra alheia./ Distancias de oceanos os conduziram como hábito/ de serōes e vigilias. Solidōes do longe/ os ensinaram a quem partilhou tédios e saudades.../ ficaram nas memórias teimosas de abandonada gente.../ presa por um fio a um país esquecido.../ Não os ouve nada nem ninguém ${ }^{8}$.

Os viajantes portugueses das esquadras da Índia levavam sua cultura tanto na memória, como notou Camara Cascudo ${ }^{9}$, quanto em signos típicos da época. Narrativas e símbolos gráficos funcionavam como códigos que transmitiam chaves essenciais para o reconhecimento e a interpretaçāo de sua civilização. Os códigos cumpriam um papel tanto de identificação do ser português, como atuavam nas transformaçōes que ocorreriam, mais tarde, como resultado das viagens através do sincretismo, hibridaçāo ou crioulização de povos e culturas ${ }^{10}$. Os códigos mais extremos, como bandeiras e vestimentas, por exemplo, refletiam o posto, a categoria e a ordem. As

8 SENA, Jorge de. 40 aros de Servidão. Lisboa, Moraes, 1979: 164-66.

9 CASCUDO, Lứs da Câmara. Literatura Oral no Brasil. José Olympio, Rio de Janeiro, 1978, $2^{\circ}$ ed.

10 Em relaçalo ao encontro do portugues com o desconhecido, consultar MACEDO, Helder, "Recognizing the Unknown: The Discoveries and the Discovered in the Age of European Overseas Expansion", Camöes Quaterly, vol. 4, N's. 1 e 2 (Spring and Summer 1992): 8-13. Sobre o mpel da imaginaçấo nos descobrimentos, consultar SlLVA, Janice Theodoro da. Descobrimentase Colanizaçăo, Săo Paulo, Ática, $2^{\circ}$ ed, 1989. 
tripulaçōes dos navios eram đivididas através de signos de classe e função: capitães e nobreza, soldados, padres, colonos e escravos. Outros códigos mais proeminentes, como os timbres heráldicos, revelavam a linhagem e a posição sócio-militar ${ }^{11}$. Os padres nāo só usavam vestimentas características como também levavam os emblemas de suas ordens, também inscritos na arquitetura religiosa na Índia, com vistas à representação de seus credos e objetivos. Os códigos narrativos incluíam a literatura oral e o folclore, com temas retirados de fontes ibéricas tais como a lírica medieval, os romances de cavalaria, o drama litúrgico e os textos da lei. As baladas cantadas como poesia popular se espalharam pela Ásia e tiveram presença particularmente forte na diáspora judaica. $O$ teatro religioso encenado a bordo dos navios funcionava como um chamariz para a conversão, uma vez que dramatizava temas retirados, por exemplo, dos contos de cavalaria, das peças que tratavam do mistério e da paixão religiosas e das vidas de santos. Até a semelhança geográfica dos lugares escolhidos para a ocupação e a colonização, a organização simbólica da arquitetura, e a forma como as comunidades de comerciantes se estabeleceram - tudo parece indicar um codigo que os portugueses duplicaram por todo o seu mundo marítimo.

Os símbolos e códigos culturais portugueses eram inscritos com freqüencia e ainda são legíveis em túmulos e monumentos portugueses presentes na costa ocidental da Índia. $\mathrm{Na}$ entrada do seminário em Rachol encontra-se o brasão de D. Sebastião (morto em 1578). Por toda a India, marcadores de pedra e cruzes em cemitérios de igrejas trazem as inscriçóes de várias geraçōes de portugueses eurasiáticos: Dias, Fernandes, Gomes, Lobo, Martins, Mendonça, Pena, Pereira, Rodrigues, Rosário, D'Silva, D'Sousa, Tomas, Vega ${ }^{12}$. No topo do Forte Korlai, isolado e castigado pelo vento, um promontório notável que se eleva a 300 pés e de onde se avista Chaul e o mar, descrito por Couto em 1602 como uma grande fortaleza, encontram-se emblemas e inscriçōes há muito esquecidas, palavras em pedras que pontuam a costa indiana, contidas entre as paredes de cidades, igrejas e fortalezas abandonadas:

11 ABRANTES, Marques de. Introdução ao Estudo da Herfldica. Lisboa, ICALP/Ministerio da Educaçio, 1992

12 Estes sáo os sobrenomes usados em Kortai, uma comunidade falante de portugues crioda, perto de Chaul (Revdanda, Kolaba Dt.), em 1993. A existencia do povoado foi apoenteda por MITTERWALLNER, Griti Von, em Chaul: Eine Unerforschte Stadt an der Westibuste Indiens. Berlin, Walter de Gruyter \& Co., 1964. 
JACKSON, K. David. Sinkings, sailors, soldiers, spice: o corpo encoberto do portuguess na f́ndia.

ESTE CASTELO MANDOV FAZER

OVIZORI DA INDLA DO FELIPHE

MZS ENOVBRO DE 1646 ANOS 9

SENDO CAPITAO DE CHAVL FE

RNAO DE MIRANDA ENRIQES E A

CABOVSE NE MAIO DE 1680 SENDO

CAPITAO DESTA PRACA CRISTOVĀO

DABREV DAZEVEDO

Forte Korlai

POR HAVER MORADO NESTE LVGAR

SAO FRANCISCO XAVIER OCC. PASSOV AO NOR

TE LHE FES ESTA ERMIDA DO

GILLIANES DE NRA. SENDO CAPIT

AO DESTA FORTALEZA. PA.

MEMORIA E LOVVOR DO SAN

TO O ANO DE 1640

Inscrição do Forte Chaul

A entrada em Goa antiga se faz por debaixo da estátua de um fidalgo portugues de armadura, exposta no Arco do Vice-rei.

A língua falada pelos viajantes portugueses representava tanto identidade como mudança. Os lingǘístas não chegaram a um acordo no que diz respeito ao nível de crioulizaçāo presente no mundo do comércio mediterrâneo, nem tampouco em relação à influência, sobre o portugués falado, de quase 100 anos de viagens exploratórias pela África. Os empréstimos que as línguas africanas e asiáticas fizeram do porlugues sāo um tópico de bibliografia considerável (ilustrado por palavras como chave, vidro, camisa, alfinete tabaco etc). Documentação posterior mostrou que dialetos crioulos parecidos se desenvolveram nas áreas de contato. Em um estudo sobre o português de Sri Lanka, Smith mostra que no inf́cio do século XVII um pidgin baseado no portugues era falado no litoral ${ }^{13}$. Comunidades crioulas haviam se formado, feitas de eurasiáticos, mestiços (conhecidos por "Topa$z^{\prime} s^{n}$ ), e africanos orientais (conhecidos pelo termo espúrio "cafres", ou "kaffirs", do portugues/árabe), que trouxeram com eles um português pidgin diferente. Os filhos de portugueses casados teriam entrado em contato com o 
R. Htstórta, Săo Paulo, n. 127-128, p. 141-162, ago-dez/92 a jan-jul/93.

pidgin ou língua crioula através de empregados domésticos negros, alguns dos quais haviam sido escravos em Goa. $O$ portuguess crioulo asiático tem sido bastante estudado por lingüistas desde o final do século XIX, muito embora considere-se que a língua indo-portuguesa, como o componente principal da identidade da comunidade, esteja no limite de sua extinção, para tornar-se em breve mais uma relíquia da ausência cultural ${ }^{14}$.

Há duas questões principais relativas aos grupos eurasiáticos falantes do português crioulo. Primeiramente, os dialetos do portugués pidgin ou crioulo, que eram a língua materna destes grupos, espalharam-se rapidamente pela Ásia no século XVI e início do XVII, e eram a língua da conversa social, e muitas vezes das práticas religiosas e legais, tanto nas sociedades coloniais inglesas como nas holandesas, até o início do século XX. Em segundo lugar, as populaçōes crioulas, que tiveram pouco ou nenhum contato com o português padrão a partir do final do século XVII, mas que, no entanto, mantiveram o traje europeu e o catolicismo romano em oposição ao grosso da sociedade, estavam sujeitas à degradação social e à exclusão dos altos cargos da administraçāo. Esta populaçāo levava uma vida de necessidades materiais como pequenos comerciantes ou artesãos, tais como alfaiates, sapateiros, zeladores de lojas de comércio, carpinteiros, ferreiros e mecânicos ${ }^{15}$.

Os contatos com a Ásia fizeram surgir um desacordo profundo nos limites da identidade portuguesa. Os fortes na costa Malabar da India mantiveram um comércio marítimo que se estendia desde Moçambique até a China (pão, porcelana, ópio, índigo, cocos, canela, drogas, cravo-da-Índia, tecidos de algodão, ouro, marfim, escravos da África Oriental) e apoiavam comunidades mistas de colonos portugueses, muçulmanos, negros, cristãos locais e hindus. A população característica da importante cidade de Chaul foi descrita por Bocarro em 1635:

A gente que mora dos muros a dentro desta cidade em cazas muy boas sobradadas de pedras e cal são duzentos Cazados Portuguezes, e sincoenta pretos Christãos da terra os quaes hus por

14 Os estudiosos principais do português crioulo na Ásia foram Adolfo Coelho, Sebastiåo R. Dalgado, Tavares de Mello, Hugo Schuchardt, Pe. Antonio da Silva Rego e José Leite de Vasconcellos.

15 Consultar Lopes, David. A Expansāo da Lingua Portuguesa no Oriente durante as séculas XV, XVII e XVII. Porto. Portucalense, 1969, $2^{\circ}$ ed.; e MACGILVRAY, Dennis. "Dutch Burchers and portuguese mechanics: Eurasian ethnicity in Sri Lanka", Comparative Studies in Society and History. 24.2: 235-63. 
JACKSON, K. David. Sinkings, sallors, soldiers, spice: o corpo encoberto do português ns f́ndia.

outros tem cada hum escravo que possa tomar armas... e a cauza de serem os escravos tam poucos he porq todas fogem pera terra dos mouros, vivem alem destes nos arrebaldes referidos e em mtos palmares e ortas dos Portuguezes $q$ estão pouca distancia da Cidade, e quasi debaixo da artelhra de seus muros, quinhentos homes cazados pretos entre christăos e gentios dos mais delles offiçiais de officios de macanicos, e ate os chandiris q são os que sobem as palmeiras a colher seu fruito, nos servirảo já na guerra contra os mesmos naturais mouros sñores da terra... 16

Quando o forte portuguess na lagoa de Batticaloa se rendeu em 18 de abril de 1638, o Almirante holandes Willem Jacobsz Coster lá encontrou 700 habitantes, descritos como 50 portugueses e mestiços, e o resto de negros, mulheres e crianças. Grupos distintos de "Burghers" portugueses e holandeses que falavam a língua crioula que, de acordo com a documentação da igreja local, s 6 se formou no século passado. Grupos étnicos indo-portugueses - sejam chamados de goeses, porto-indianos, "East Indians" de Bombaim ou "Burghers" de Sri Lanka - há muito assimilaram e mantiveram costumes, religião, língua e folclore iniciados através de contatos com os portugueses. As etimologias e os termos anglo-indianos coloquiais estudados por Yule e Burnell (1886) revelam uma influencia ampla e o conhecimento de vocabulário portugues ${ }^{17}$. A cultura e a língua portuguesas estão presentes em muitas comunidades na fndia e no Sri Lanka, dando voz a relfquias materiais do passado através do sincretismo da língua, raça, costumes, arquitetura, culinária, música, literatura e folclore. A perene contribuição portuguesa à civilizaçăo indiana consiste da criação de um povo indo-portugues distinto, ainda em grande parte não-reconhecido, cuja língua, história cultural e identidade såo o produto do cruzamento de fontes européias, africanas e asiáticas. A seguinte quadra popular indo-portuguesa e crioula, cantada em Sri Lanka, que se encontra na coleção de manuscritos de Hugh Nevill da Biblioteca Britanica, representa a fusão de culturas e línguas sob o signo das viagens maritimas:

Sie Kere canta, Canta dratoe purtieges, Numiste canta, Mallaiye landes.

16 PeREIRA, A.B. de Bragança, Anquivo Português Oriental. Bastora, Tipografia Rangel, 1937, Tomo IV, Vol. II, Parte I: 197.98.

17 YULe, Henry e BURNEL, A.C. Hobson Jobson A glassary of collogrid Anglo-Indian wards and phrases. New Delhi, Munshiram Manohartal, 1979, 37 ed. Reimpressto de 1886. 
R. Histórfa, Såo Paulo, n. 127-128, p. 141-162, ago-dez/92 a jan-jul/93.

[Se quer cantar, Canta direito o português, Nāo canta, o holandês da Malásia ;

Nevill 59/101

As rotas marítimas da Índia expandiram não somente as fronteiras da Europa renascentista, mas também alteraram a identidade dos viajantes. $O$ processo de transformação cultural ou sincretismo, de português para indoportuguês, freqüentemente visível no nível da narrativa e da cultura, como é ilustrado pela tradiçâo oral, coloca em pauta o problema da dialética ou alteridade. Retirei do estudo de William Desmond sobre o desejo e a alteridade elementos para a feitura de um quadro teórico ${ }^{18}$. Os códigos da identidade portuguesa utilizados nas viagens enfatizavam a semelhança, a identidade, a unidade - para empregarmos os termos de Desmond - e colocavam em segundo plano o encontro desejado com o que se imaginava ser 0 outro, a diferença, a pluralidade. A viagem é narrada com a ajuda de mitos e fantasia, o que projeta os temas utopicos do ocidente de erotismo e exotismo. A fantasia é dotada de um corpo físico e textual diferente, capaz de transcender os confins do ser através da identificação com o corpo e o texto alienígenas. Os vice-reis portugueses na Índia criaram um vice-mundo, ao mesmo tempo uma afirmação e alteraçāo de identidade. A ambigüidade representa tanto a vitória e o sacramento do ser, como uma metáfora de regeneração cultural, quanto a transformaçāo do corpo e da identidade, como uma metáfora de perda e dissoluçāo cultural. Até a utopia da resolução de todas as diferenças - comunhão e satisfação - traz a tendéncia oculta de um desejo complementar de alienação e alteridade.

A poesia popular indo-portuguesa, ao expressar códigos e práticas culturais, ilustra as dimensōes da nova identidade eurasiática. $O$ mecanismo cultural de contato é parte do que é cantado na tradição popular, descrevendo os ritos comunitários de nascimento, namoro, casamento, celebraçōes, destino e morte, por exemplo. A identidade indo-portuguesa é conceitualmente instável, em parte porque a narrativa mitifica e incorpora a mudança ou a diferença nela mesma, reduzindo assim o outro, neste caso o eurasiático ou mestiço, a uma variante ou desviante da mesma identidade. O próprio ser de cada um também se modifica constantemente, conforme expresso no verso de Camōes, "Todo o Mundo é composto de mudança", outro ponto de vista que

18 DESMOND, William. Desire, Dialect and Othemess: An Essay on Origins. New Haven, Yale University Press, 1987. 
JACKSON, K. David. Sinkings, sailors, soldiers, spice: o corpo encoberto do portuguess na fndia.

incorpora a diferença. Na epopéia Os Lusiadas (1572), de Camōes, a história e a mitologia se interpenetram: os navegantes portugueses sāo protegidos por Vénus, ao nivel da historia, narrativa e identidade, enquanto viajam por terras habitadas por demônios mitológicos de várias origens e à mercê de forças subliminares da mente e da natureza. Um dos mitos mais sugestivos que denuncia a busca de Vasco da Gama de unidade e incorporação-seja militar, cultural ou física - é o do gigante Adamastor, que guarda o tempestuoso Capo da Boa Esperança no quinto canto do poema épico. Ele se formou a partir do ar acima do mar escuro e falou numa voz aterrorizante, condenando os portugueses por sua presunção e por fomentar guerras, naufrágios e catástrofes, como castigos pela invasão de regiōes proibidas, em empreendimentos inúteis. Ele prenuncia e erotiza as mortes de Manuel de Souza Sepúlveda e sua esposa $D$. Leonor, que morre abraçando seu amante nas areias quentes da África, depois de ter sido despida por selvagens. Também o gigante é vítima de um amor frustrado, pois tendo perseguido a Nereida Thétis, com um ardor tão cego, quando correu para possul-la à força e prendê-la em seus braços, percebeu, demasiado tarde, que estava abraçando os penhascos rochosos do Cabo. Sua carne então tornou-se terra, enquanto Thétis continuou a tormentá-lo com ondas envolventes.

Em sua busca de cristãos e especiarias, sob o olhar contemplativo da Ásia, os navegantes portugueses colocaram sua identidade em risco, motivados pela diferença e pelo entranhamento do que era para eles um mundo oculto. As viagens alteraram fronteiras físicas e geograficas, transpondo os viajantes portugueses, literal e metaforicamente, para além de si mesmos, em direção a um estado de alteridade; lá, os códigos culturais a que deram corpo, tão distantes de suas narrativas e origens simbólicas, adquiriram novos significados. Os sinais indeléveis da identidade ocidental foram lidos de uma forma completamente diferente pelos artistas japoneses cujas telas de nambam retrataram, com sagacidade e de forma caricatural, a chegada dos portugueses: as calças com pernas em forma de balāo dos uniformes das viagens ultramarinas, os colarinhos enfeitados de folhos e os lenços brancos, os bigodes, os cavanhaques, os narizes grandes, os olhos penetrantes, e, acima de tudo, os chapéus sempre associados aos portugueses, que por toda a Ásia eram conhecidos como gente de chapéu. As ilustraçōes de outras criaturas trazidas ao Japão pelos portugueses mostram como, comparativamente, foram retratadas como fetiches de corpos estranhos e exóticos: um papagaio preso por dois dedos; um marinheiro de pele visivelmente mais escura passeando com um cachorro de rabo estranhamente longo; escravos negros equilibrados de forma acrobática no cordame dos navios. Observando a estranha procissão de dentro da proteção simbólica da moldura da porta da 
R. Histórla, Såo Paulo, n. 127-128, p. 141-162, ago-dez/92 a jan-jul/93.

casa, estão uma mãe japonesa e sua filha, ambas espantadas. Nestas telas, os portugueses são os outros ${ }^{19}$.

No contexto do exotismo, desde o início a viagem representava tanto a afirmação como a perda do ser, expressos nos temas literários da utopia e do estranhamento, respectivamente ${ }^{20}$. Uma viagem que revivia o tema clássico da busca - a partida, as aventuras, e a volta do herói - começava pela afirmação do ser para então reintegrá-lo às suas origens míticas, depois de rituais de exílio, sacrifício do corpo, e perda de identidade. $O$ tema da perda simbólica do ser parecia fazer parte do importante tema religioso da volta às origens: a obsessiva procura portuguesa do reino utópico de Prester John e dos cristãos perdidos da Etiópia ${ }^{21}$, e a tentativa de encontrar o túmulo de São Tomé na Índia. Em termos abstratos, identificar-se com as origens perdidas significava equiparar o ser a sua própria ausência e vestígios. Pode-se dizer que os portugueses navegaram para entrar em contato com seus próprios corpos "perdidos", e então completar a si mesmos: lê-se no soneto de Camões que "Transforma-se o amador na cousa amada". Ademais, recuperar um corpo ao mesmo tempo perdido e desejado que $\epsilon$, simbolicamente, deles próprios, mesmo que seja um corpo religioso, significa, no processo de luta para definir o ser, dar relevo ao papel de um desejo oculto $e$, a partir de uma perspectiva moderna, a um erotismo patológico. Em 1982 fotografei uma pedra antiga atrás da Catedral de São Tomé, em Mylapore, que exibia uma inscrição com três palavras em português, dizendo "AQUI JAZ NADA". Estas palavras misteriosas são o símbolo máximo, ainda que ambíguo, da negação ou perda do ser. É como se, ao viajar, os navegantes portugueses estivessem transformando o seu antigo ser em relíquia. Na esteira do tema da busca, o corpo se reconstitui em outro nível, depois de ter sido desmembrado pelas viagens, implicando a volta de um herói mudado e rejuvenecido. Este tipo de simbolismo corrobora uma interpretação das transformações raciais e culturais do mundo indo-europeu como metáfora; por exemplo, a miscigenação como uma metáfora de incorporação entendida como afirmação do ser,

19 Três das telas namban encontram-se no Museu de Arte Sacra (Lisboa), no Museu de Kobe (Japão) e no Kimball Museum (Ft. Worth, Texas).

20 Para estudos sobre a utopia consultar SARAIVA, Antônio José. Historia e Utopia: Estudos so. bre Vieira. trad. Maria de Santa C.ruz. Lisboa, ICALP/Ministério da Educaģao, 1992. Utopias e perusamiento utopico. Madrid, Espasa-Calpe, 1982 e La utopta e las utoptas. Madrid, Asociacion Cultural Hispano-Norteamericana, 1975.

21 Consular GUMILEV, L.N. Searches for an Imaginary Kingdom: The Legend of the Kingdom of Prester John. R.E.F Smith, trad. Cambridge, Cambridge University press, 1988. 
JACKSON, K. David. Sinkings, sailors, soldiers, spice: o corpo encoberto do portugues na India.

mas que também significava, freqüentemente, a perda do outro. Não se permitia que a identidade permanecesse ambigua ou plural nos avatares indo-portugueses.

Encontrei elementos convincentes que me permitem interpretar os códigos da identidade portuguesa ou indo-portuguesa na antítese do drama barroco-maneirista, onde os extremos se encontram num concordia discors. A relação é de subordinaçāo ou até de anulaçāo de um pelo outro. No contexto dos códigos simbólicos, as oposições de identidade (ou ser) e estranhamento (ou alteridade) são partes de uma narrativa dividida entre ortodoxia (português) e desvio (indo-português). Essa dialética opera tanto no nível histórico como simbólico ${ }^{22}$. O contraste barroco aparece nos trabalhos de poetas como Camões (que esteve na Ásia entre 1552 e 1570) e que cultivava a arte do paradoxo, ou "desconcerto", através do jogo de oposiçōes no qual papéis culturais estão sujeitos a torções inesperadas e repentinas: em sua "Endechas a Bárbara escrava", por exemplo, Camóes descreve sua escrava, cujo nome significa "selvagem", como "Aquela cativa/Que me tem cativo". Há outras interpretações modernas das viagens como metáfora, tal como a do poeta português Fernando Pessoa, que entendeu sua "mensagem" como misticismo histórico, e vislumbrou uma força subliminar governada pelo destino que iria revelar os poderes e significados ocultos dos códigos ${ }^{23}$. Pessoa estava tentando descrever as dimensões épicas desconhecidas, as conseqüências humanas e a motivação que estavam por trás das viagens, as quais, talvez, sejam apenas um símbolo. Para o escritor italiano moderno Antonio Tabucchi, as viagens foram motivadas pela nostalgia do possível ${ }^{24}$. Viajar representava a fuga paradoxal do ser em direção a formas absolutas e plurais. A "presença" portuguesa na Ásia, nesses termos, tornou-se uma forma universal de alteridade, e a nostalgia da distância pura e abstrata foi uma de suas forças motoras.

A viagem dos portugueses à Ásia virou uma metáfora de alteridade e ausência inerentes, através das quais os viajantes criaram, em última instância, formas latentes de si mesmos nos povos que iriam assumir a identidade

22 TAUSSIG, Michael. Mimesis and Alserity: A Particular History of the Senses. New York, Rou-

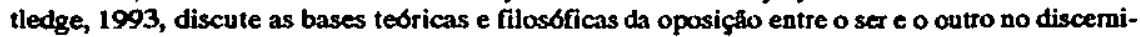
mento da etnografia e da sociedade.

23 PESSOA, Femando. Mensagem. Lisboa, Parceria Antônio Maria Pereira, 1934; Message, Jonathan Griffin, trad Londres, The Menard Press, 1992.

24 TABUCCHI, Antônio. "Os objectos em Alvaro de Campos", Revista de Cultura Macau, a"5 (Abril/Maio/Junho 1,988), Ano 2, $2^{\circ}$ vol.: 77-80. 
R. Hbt6rin, Så Paulo, n. 127-128, p. 141-162, ago-dez/92 a jan-jul/93.

deles. A viagem do corpo pode ser explorada como uma metafora tanto no contexto dos códigos de identidade histórica como subliminar, inevitavelmente levada por cada viajante. $O$ que me interessa aqui são os dois temas discordantes que mencionei, sugeridos pela viagem do portugues à Ásia lida como metáfora: utopia e alteridade. A metáfora, mais uma vez, assenta-se em um conflitante drama barroco de identidade, oscilando entre representaçōes de salvação e perdição, totalidade e vazio, perfeição e putrefação, completude e ausência, história e desejo, paraíso e inferno. Viajar para a Ásia significava, por um lado, a possibilidade de uma apoteose, de uma satisfaçáo ou o alcance da perfeição do corpo através da busca de uma utopia mundana e de uma salvação celestial; por outro lado, a viagem reforçava o mito do sacrificio do corpo e da perda do ser através de formas grotescas de estranhamento e alteridade. A utopia alia-se a Eros como identificação profunda do ser, ainda que se encontrem em uma geografia proibida, sem área demarcada, que corresponde a um espaço imaginado de licensiosidade erótica. Essas representações conflitantes trazem à tona o jogo barroco dos opostos, de modo que o corpo vazio veio a refletir o corpo perfeito e o corpo ausente virou o corpo eterno.

A peça "O Milagre de Santa Apolonia", encenada nas naus, conforme descrito por Mário Martins ${ }^{25}$, é emblemática da dialética barroca e aponta para o simbolismo tanto da perda do ser como da busca erótica. A peça dramatizava cenas terríveis de torturas que, na presença do imperador, de damas da nobreza e da burguesia, foram impostas a Santa. Tais espectadores sentavam-se entre o Céu (com anjos e músicos) de um lado e o Inferno (com diabos) do outro. A atuação pode ser lida como um subtexto do código do corpo através do tema do martírio da vítima inocente e especialmente de uma jovem, como observa a curiosidade de Mário Martins. Ao mesmo tempo em que representa o tema da salvação, a peça sublima o oposto, a perdição, através da profanação e da mutilação do corpo, que é feita com toques velados de violência erótica. Lida como uma metáfora da conquista, a representação do martírio da Santa na peça do século 15 também traz um subtexto de sacriff́cio e mutilação do corpo. Outras narrativas memoráveis de perda dominam os relatos portugueses a respeito da Ásia, no século XVI. Do grande número de viajantes, cerca de trezentos em cada navio, aproximadamente um terço se perdeu em naufrágios, conforme se le no relato dramático da história trágica do mar (1735), de Bernardo Soares Brito. Muitos outros morreram em

MARTINS, Mírio, S.J. Teatro Quinhentista nas Naus da India Lisboa, Ediçoes Broterria, 1973. 
JACKSON, K. David. Sinkings, sailors, soldiers, spice: o corpo encoberto do portuguas na fndia.

decorrencia de doenças e guerras ${ }^{26}$. Fernão Mendes Pinto, em suas famosas viagens, descreve as glórias e as intensidades de sua vida na Ásia: em sua primeira viagem para o Japão teve a companhia de São Francisco Xavier e foi feito prisioneiro e vendido como escravo dezessete vezes ${ }^{27}$. Seus relatos a respeito de outros governantes e de costumes bizarros foram interpretados recentemente como uma forma sutil de sátira à identidade portuguesa e aos valores do império através das vicissitudes do corpo. Em "Sobolos rios", Camōes narra o exílio, o cativeiro e a escravidão do poeta, através de uma canção retirada de seu contexto original, já que funciona como uma recapitulaçāo histórica do Salmo 136. Através do poder do desejo, da memória e da imaginação, o poeta exilado restaura a autenticidade de sua canção na medida em que associa a recuperação da identidade (a busca do antigo corpo) à repatriação à geografia nacional e religiosa da salvação (Sião e Portugal). A utopia imaginada da perfeição, da unidade e da completude ultrapassa o desejo erótico de um submundo de auséncia, equiparando, desse modo, a liberdade à satisfação sensual do ser e ao domínio da narrativa.

Em seu estudo sobre as metáforas de incorporaçẫo, Marjorie Kilgour explica a compulsão de unir os opostos barrocos com a idéia de que a identidade $e ́$ um conceito ambivalente ${ }^{28}$. Afirmar uma identidade implica reconhecer o seu oposto, da mesma forma que a busca de uma identidade completa implica render-se à diferença. A comunhão e o canibalismo são ambos metáforas de incorporação: eles tentam trazer o que está de fora, $e$, portanto, o que é estranho e ameaçador, para o interior. Colocar tudo no interior do corpo significa, ao mesmo tempo, universalizar e alterar o ser. Tal busca de uma unificação total implica a reconstituição simbólica do ser em outro nivel (comunhão), uma vez que tenha sido desmembrado metaforicamente nas viagens (canibalismo). No caso de Santa Apolónia, o martírio e a perfeição cedem ao corpo eterno (comunhão), enquanto a história profana as relíquias (canibalismo). As metáforas de incorporação expressam a interdependencia paradoxal entre totalidade e alteridade; conquista e submissão; realização erótica e sublimação simbólica. A metáfora de incorporação im-

26 BRITO, Bernardo Gomes de. Históriatrágico-martima. Porto, Livraria Civilizaçăo, 1942-43. 6 vols. E Damiso Peres. The Tragic History of the Sea, 1589-1622. Charles Boxer, trad. $2^{\circ}$ série, $0^{\circ} 112$. Londres, The Hakluyt Society, 1957.

27 Publicado em Lisbos em 1614, o Peregrinaxam foi traduzido e anotado recentemente como Tranels of Mendez Pinto. Rebecca Cat, trad. e Ed. Chicago, University of Chicago Press, 1989.

28 KJLGOUR, Marjorie. From Communion to Canibalism. Princeton, Princeton University Press, 1990. 
R. Hlstória, Såo Paulo, n. 127-128, p. 141-162, ago-dez/92 a jan-jul/93.

plica um retorno heróico através da imagem de um corpo que abarca tudo; conquistas utópicas, no entanto, disfarçam, em seu apelo à unidade e à universalidade, a supressão e a apropriação do outro, até mesmo do ser que se tornou outro. As viagens, deste modo, constróem e colocam em movimento uma fábula de sua própria identidade através da invenção, e, depois, da incorporação de um mundo exterior e alienígena, neste caso a Ásia. É assim que Kilgour ve nas viagens coloniais uma forma de canibalismo, uma vez que suprime de forma agressiva as diferenças culturais das quais sua riqueza de significados depende. $O$ canibalismo é a metáfora que guia até a forma mais idealista de conquista, conhecendo ou possuindo objetos; e é especialmente subversivo em sua tolerância das diferenças e em sua insistência numa identidade européia única. $O$ mito da plenitude e da comunhão na reconciliação dos opostos parece ligado ao seu oposto, o ato de devorar as diferenças culturais, seguido de uma sensaçăo de alienação e vazio.

A peregrinação aos túmulos dos santos é parte do mito da perda e da recuperação da identidade carnal. A profanação do corpo não é incompatível com os restos sagrados, já que o canibalismo do corpo liga-se à salvaçāo do ser. A estória do corpo santo, como no drama de Santa Apolónia, só pode ser contada na linguagem da violação e do desmembramento, ilustrada pelos dois corpos mais famosos da Índia portuguesa, São Tomé e São Francisco Xavier $^{29}$. Os corpos santos recapitulam o tema da busca que o herói empreende no nível metafórico da consciência carnal e subliminar e do poder.

\section{DE MYLAPORE A KODUNGALLUR-AZHICODE}

A história do cristianismo na India está profundamente ligada aos corpos de santos, começando em 52 d.C. com a chegada de São Tomé, o Apóstolo, que é perfurado por uma lança e martirizado em Mylapore, a 3 de julho do ano 72 d.C. O túmulo de Sāo Tomé em Mylapore, ou Berth-Thuma, tornou-se um local de peregrinação - especialmente para famflias sírias de Malabar e até de viajantes da Síria - e fonte de milagres como resultado da prece ao pé do túmulo ou da poeira retirada do local. Entre os ocidentais que

29 Para conhecer a bistoria destes dois corpos santos, consultar MENACHERY, George e CHAKKALAKAL, Fr. Werner. Kodungallur: City of Saint Thomas. Kodungallur-Azhicode, Marthoma Pontifical Shrine, 1987 e Velha-Goa: Guia Histórico: Editado por ocasiōo da Expasiçōo das Rellquias de S. Freacisco Xavier pelo Quano Centenírio da sua Morte 1552-1952 Gos: Imprensa Nacional, 1952. 
JACKSON, K. David. Sinkings, sailors, soldiers, spice: o corpo encoberto do portugues aa lndio.

narraram sua visita ao túmulo antes da chegada dos portugueses encontramse o Rei Alfred o Grande, da Inglaterra, que voltou com "um esplendor exótico, pedras preciosas e perfumes", no século 9; John de Monte Corvino, um Núncio no Oriente, que, no final do século 13, esteve por treze meses em Mylapore; Marco Polo, que notou em 1292 que o túmulo do santo era venerado tanto por cristāos como por sarracenos; um Franciscano, representante do Imperador da China, que lá esteve em 1349; e o navegador veneziano, Nicolo Conti, que em $1430 \mathrm{fez}$ comentários a respeito de uma igreja grande e ricamente decorada. A estória épica das relíquias de São Tomé ilustra a dinamica da busca do corpo sagrado, na qual se interpenetram motivaçōes históricas e religiosas, constituindo-se um paradigma para as figuras (corpos) religiosos portugueses catorze séculos depois.

A "maior parte" das relíquias foi transferida (roubada, de acordo com alguns relatos) para Edessa, na Mesopotamia (atualmente Turquia), ao mais tardar no século 3, tendo sido transportada até lá por um mercador. Uma parte dos hinos de São Efraim (morto em 373), que narra os supostos pensamentos do Diabo, diz: "o Apóstolo que eu matei na f́ndia me suplantou em Edessa... O mercador trouxe os ossos; nāo, na realidade esses o trouxeram a ele "(4). Quando terminaram a construçāo de uma Basflica em 394, as relíquias foram para lá transportadas, mas não sem antes assegurarem que partes delas seriam expostas para veneraçāo em três igrejas italianas (Nola, Brescia e Milāo). A distribuiçāo das relíquias cumpre um papel importante na patologia da veneração e é testemunha do poder milagroso atribufdo ao corpo. Em 753 as relíquias remanescentes foram guardadas numa caixa de prata que foi suspensa do teto por correntes de prata. A peregrinação das relfquias, no entanto, estava longe de chegar ao fim, já que o controle de Edessa passou dos Imperadores de Constantinopla para os Sarracenos e depois para os Cruzados e até para o Emir de Musal. Devido ao pođer crescente do Islá e à destruição da Baślica de São Tomé e depois de terem permanecido em Edessa por oito séculos, as rellquias foram transportadas, em data desconhecida, para Chios, uma ilha no Mar Egeu. No dia 17 de junho de 1258, uma esquadra do Príncipe de Tarento levou as relíquias para uma nova catedral dedicada a São Tomé, em Ortona, na costa do Mar Adriático.

Quase trezentos anos depois, em 1556, as relíquias encontraram o cesastre quando a cidade foi bombardeada por uma frota turca que destruiu as igrejas. Em busca de tesouro, os navegantes explodiram o retábulo e a pedra que cobria as relfquias do Apóstolo. Depois descobriu-se que os restos sagrados haviam sido preservados sob os escombros, com exceção da cabeça, que foi encontrada mais tarde, e, apesar de danificada, foi totalmente reconstituida. Desde entāo as relfquias jazem numa urna de bronze, sob um altar de 
R. Hist6rla, Sáo Paulo, n. 127-128, p. 141-162, ago-dez/92 a jan-jul/93.

mármore. A cabeça, montada sobre um busto de prata, é exposta para a veneração pública nos dias de festa. Seguindo a logica do hino de Săo Efraim, pode-se dizer que o braço direito do Apóstolo retornou a Kerala no dia 6 de dezembro de 1953, evento que contou com a presença de Sua Eminencia Cardeal Eugene Tisserant, Decano do Colégio dos Cardeais. A peça entrou pelo rio Periyar numa procissão de barcos decorados, e foi alojada no Relicário Pontifical Marthoma, construído em Kodungallur, um local considerado pelos cristãos de Kerala como o centro da Igreja indiana, em tempos anteriores à chegada dos portugueses. $O$ relicário foi projetado como uma miniatura đa Baślica de São Pedro, em Roma, completo com colunatas.

\section{CORPO INCORRUPTO/ESTADO CORRUPTO}

São Francisco Xavier veio para a Índia em 1541, onde seu misticismo profundo e simpatia com o povo ocasionaram milhares de conversర̋es $e$ alguns milagres. O Santo viajou pela Ásia portuguesa, começando em Goa, Chaul e na costa da Índia e do Sri Lanka. Em 1549 viajou por mar até o Japão, desembarcando em Kagoshima, onde permaneceu por mais de dois anos. $\mathrm{Em}$ 1552 regressou a Goa e navegou novamente à China. O Santo morreu na ilha de Changchuen, dando início à saga do corpo milagroso e incorrupto. $O$ tratamento dos restos mortais sugere um simbolismo antitético que dá corpo ao drama barroco portugues: o corpo perfeito se transforma no corpo ausente; o corpo completo se transforma no corpo desmembrado. Depois de embalsamado e enterrado na China por três meses, quando as relíquias foram transferidas para a viagem à Goa, percebeu-se que estavam perfeitamente conservadas. Numa atitude precursora de procedimento futuro, um pedaço da perna foi retirado e notou-se que a carne estava fresca e cheirava bem. Em Malaca, o governadór colocou São Francisco Xavier numa cripta tão pequena, que vários ossos tiveram que ser esmagados ou quebrados. Ao chegar à Catedral de Bom Jesus, em Goa, o corpo foi exposto à reverencia pública, como acontece regularmente até os dias atuais. Uma certa Isabel de Caron, ao beijar os pés do Santo em 1552, arrancou-lhe o dedo mindinho, produzindo uma hemorragia que assustou os presentes. Por ocasião de sua morte, Isabel devolveu parte da relíquia sagrada, que agora se encontra preservada na sacristia para ser beijada pelos fiéis, e também presenteou o Santo com uma diadema de prata. Em 1655, uma capela com cenas da vida e dos milagres do Apóstolo do Oriente foi preparada para receber uma caixa majestosa de prata e pedras preciosas, presenteada pelo Duque da Toscania. Nas cenas de milagres gravadas, o Santo aparece operando a ressurreiçăo de mortos; curando surdos, mudos e doentes; batizando tres Reis das Ilhas 
JACKSON, K. David. Sinkings, sailors, soldiers, spice: o corpo encoberto do portugués na fadia.

Maldivos; recebendo de un caranguejo um crucifixo que teria cafdo no mar; adocicedo a água do mar numa viagem à China; dando comunhão elevado a uma altura de tres palmos do chão; e aparecendo depois de morto a Catarina de Chaves.

Em 1615, no entanto, a distribuiçāo das relíquias se iniciou, sem compensação, com a remoção do braço direito do Santo. A parte de cima foi enviada a Roma, a de baixo foi dividida entre Malaca e Cochim e omoplata foi destinado a Macau. O corpo permaneceu incorrupto nos séculos 18 e 19, como se conferiu pela observação e exposição pública, mas o desejo pela carne e ossos santos era tão grande que as víceras foram removidas. Em 1779, os governadores e vice-governadores assumiram os cargos na Baślica através de uma cerimónia de entrega de um cetro incrustado de esmeraldas que era guardado no túmulo do Santo, associando, deste modo, o Estado corrupto (a "lenda negra" de Winius, cf. nota 31 ) ao corpo incorrupto. $O$ monumento de 1504 à memória do criador da Basílica, D. Jerônimo Mascarenhas, revive símbolos medievais de Estado, com seu capacete e peito de armas encouraçados, escudo e brasão, cenas esculpidas que contam sua vida, e inscrições historicas acima da entrada da Catedral. Os dois únicos exames anatómicos da relíquia, conduzidos pela Escola de Medicina de Goa no final do século XIX, e, novamente, em 1952, confirmaram a mutilaçāo e o desmembramento generalizado. O mais recente aponta a separação da cabeça do resto do corpo, a qual, no entanto, pode ser vista em Velha Goa e é ocasionalmente exposta para veneraçăo. A metáfora da adoração pública é o corpo rasgado e ausente, que $́$ universalizado através de seu desmembramento e tornado completo no nível simbólico de seus poderes miraculosos. S6 se pode imaginar o que teria acontecido com a cultura indo-portuguesa se Isabel pudesse ter levado toda a relíquia para casa.

\section{UTOPLA DO CORPO}

O corpo desejado indo-português era, ao mesmo tempo, santo e libidinoso, o mesmo e o outro, sagrado e pagão, como mostra a relíquia de São Francisco Xavier e a dialética da perfeição e da putrefação. O corpo podia simbolizar a salvação religiosa e a utopia clássicas: tanto reverencia como profanação, acompanhadas da migração, ou orientalismo, do corpo-relf́quia. Ao considerar os temas do desejo e das origens, Desmond observa que a recuperação da totalidade do ser implica um desejo ambiguo e irrequie to pela diferença (migração do ser); e um desejo pela alteridade que pode vir a rejeitar a diferença através do alcance do conhecimento do que é definitivo (apoteose ou plenitude do corpo). Cada possibilidade pode ser corroborada 
R: Histórta, Săo Paulo, n. 127-128, p. 141-162, ago-dez/92 a jan-jul/93.

através do contraste das ilustraçōes narrativas do eros português ou indo-português.

Depois da conquista de Goa em 1510, Afonso de Albuquerque decretou que a miscigenaçáo seria o objetivo da política oficial, e a nona reinol ou mestiça se tornou, ao final, a musa da sociedade crioula da poesia popular, um objeto para ser desejado e possuído:

Vos de minhe frontie, Basoe de Koráal,

Nona mea donsala, Nona portugáál.

[Vocé na minha frente, lábios de coral, minha donzela, Senhora portuguesa];

Nevill 53/58

Singelle nona Singelle nona, Veeanda lava, Savam nuthen bolsa nuthen, Korpuper roosa. [Moça singalesa, eu a vi tomando banho, Sem sabāo, sem bolsa, roçando o corpo].

Nevill 57/43

A narrativa popular é um texto de prazer, cuja musa é cantada simultaneamente nos níveis da celebração e da memória, da inovação e do reestabelecimento de antigos preceitos:

Toma vi rabana nona, vamos nos canta, Pussa oen cadeira nona, diante santa.

[Toma a rabana senhora, vamos cantar, Puxa uma cadeira, senta em frente]

Cantigas 36

A poesia e a canção crioulas trazem à luz rituais de desejo, namoro e casamento, dos quais uma comunidade indo-portuguesa separada surgiu:

Bossa bossa baila, Bonitoe baila, Bossa

Jatoe per da gosto, Eau Joento per Kassa.

[Seu estilo de bailar é bonito,

Seu jeito dá gosto, eu estou aqui para casar]

Nevill 54/88

A mulher indo-portuguesa é descrita como um ser sensivel à noçáo de classe social. 
JACKSON, K. David. Sinkings, sailors, soldiers, spice: o corpo encoberto do português na lndia.

Amor ja falla, minha junto lo morre, Quando olha pobreza, ella ja salta ja curre, [Meu amor diz que ficará comigo até a morte, Quando viu minha pobreza, deu um salto e correu embora],

Nevill 51/21

E o foco de uma libido narrativa fora de lugar:

Nono de Colombo, Sava botha boloe, Maridoe ne brassoe, Amnigo ne Koloe. [Senhora de Colombo, Sabe fazer um bolo, Marido no braço, Amigo no colo].

Nevill 53/64.

Em contraste com a versátil musa indo-portuguesa, as ninfas da mitologia ocidental clássica habitam a "ilha namorada" que Camōes vislumbrou no nono canto de Os Lusiadas, como uma recompensa para Vasco da Gama e seus marinheiros. A. Barlett Giamatti a inclui entre as utopias dos jardins europeus renascentistas; como tal, é um símbolo de unidade e de harmonização da diferença ${ }^{30}$. Preparadas por Vénus e pelo Cupido, as Nereidas vão para a ilha "com mil refrescos e manjares/Com vinhos odíferos e rosas,/... Fermosos leitos, "onde o amor ardente pode responder à paixāo, e assim liberar os marinheiros de seus desejos fatais. Venus convida os marinheiros a aportar na ilha bela e fresca, dotada de uma natureza viçosa, sem nenhuma escassez. Camões invoca a metáfora da caça, tão apropriada à experiência colonial, e os marinheiros procuram diversão. Ao descobrir a presença das ninfas, Velloso entoa rem peã em louvor da điferença como personificação do prazer: "Se inda dura o Gentio antigo rito?... Mais descobrimos do que humano espírito? Desejou nunca..." A associação entre paganismo e prazer é suspensa, no entanto, já que o narrador logo duvida que estas criaturas paradisfacas - ninfas banhando-se na ribeira - não sejam mais do que criaçōes de seus próprios sonhos e imaginação. As ninfas nuas, fingindo fugir, permitem-se ser capturadas, e habilidosamente conquistam os conquistadores exaustos, num extase de amor. Comparáveis a Bárbara, a escrava que mante-

30 GIAMATTI, A. Bartlett. The Earthly Paradise and the Renaissance Epic. Princeton, Princeton University Press, 1966. 
R. Hbtórta, Săo Pado, n. 127-128, p. 141-162, ago-dez/92 a jan-jul/93.

ve Camóes cativo, as ninfas exercitam seu poder invertido sobre os heróis conquistadores. Mas o subtexto sugere que os objetos do desejo colonial queriam, eles mesmos, ser possurdos, na fatalidade quase mftica atriburda às viagens. A união dos navegantes e das deusas promete camaradagem, fé e felicidade eternas, numa utopia do corpo que supera todas as diferenças.

A deusa Tétis, líder ẹtre as ninfas, é reservada para o ilustre Vasco da Gama. O prêmio adicional que ela lhe dá é revelar-lhe o destino imutável e os segredos que restam da esfera celeste, ao levá-10 até o topo de uma montanha para ver um cristal e uma miniatura do universo feita em ouro. Num reconhecimento profético da geografia cultural, ela conta a história do futuro, ao mesmo tempo em que arma Vasco da Gama com o segredó da fama e da imortalidade que leva a posse da Ilha de Venus: "Ou dai na paz as leis iguais, constantes,/Que aos grandes nāo dem o dos pequenos". Tal conselho talvez seja a vingança de Camóes contra o Estado corrupto da India portugue$\mathrm{sa}^{31}$. Tétis e Vasco da Gama partem, em companhia das ninfas, para uma viagem eterna com provisões nobres, "Por mais tempo que o Sol o mundo aquente". A viagem que empreendem confirma o tema da salvaçăo, completa com a plenitude do corpo completo, mas também ausente.

A viagem como busca, no entanto, devolve o herói às suas origens e a uma realizaçāo final de seu desejo, enquanto as naus chegam ao Rio Tejo e "houveram vista do terreno/Em que nasceram, sempre desejado". A carne se torna terra novamente, a qual, ao contrário do imerecido Adamastor, equipara - extase do desejo aos códigos de identidade nacional. A apoteose mítica do corpo e seus desejos é completada, por fim, através do conhecimento e do reencontro com o ser. Seguindo as tradiçōes das narrativas ocidentais, 0 retorno à iđentidade é a recompensa para a conquista metafórica da mudança e da diferença. $O$ paradoxo que resta da viagem à India - a imigração da identidade ocidental à Ásia - é que a recuperação do corpo e a reuniáo como seu lugar de origem ocorreram as custas de uma identidade indo-portuguesa diversa, uma que havia tornado possivel a busca narrativa complexa e a dialética cultural do império maŕtimo, mas que os portugueses na India não souberam, afinal, reconhecer, valorizar, respeitar ou manter.

Traduzido por Leonardo Mendes, M.A. (Universidade do Texas em Austin)

31 WINIUS, Gearge D. The Black Legend of Portuguese India New Delht, Concepn Publishing. 1985. 
JACKSON,K. David. Sinkings, sailors, soldiers, spice: o cotpo encoberto do portugrès na fndia.

ABSTRACT: In this essay which interprets the symbolism of voyages of discovery and their cultural and linguistic contacts, the author examines the theme of identity thrungh the meaning of the body. It presentes mare examples of folklore from mixed or miscigenated communities in Ásia, such as the Indo-Portuguese, that resulted from contacts between Portugal and the Orient. Using concepts from the Baroque, the author studies in the lives of Saints the concept of the body divided between unity/perfection and loss/dismemberment. The Western theme the recovering of lost identity works to deny the val oe of the Indo-Portuguese or creole cultures that the voyages created.

KEY-WORDS: creole, body, ideotity, travels, indo-portuguese 